\title{
Characterization of the human tRNA-guanine transglycosylase: Confirmation of the heterodimeric subunit structure
}

\author{
YI-CHEN CHEN, ${ }^{\mathbf{1}}$ VINCENT P. KELLY, ${ }^{2}$ STEFANIE V. STACHURA, ${ }^{\mathbf{1}}$ and GEORGE A. GARCIA ${ }^{\mathbf{1}}$ \\ ${ }^{1}$ Department of Medicinal Chemistry, College of Pharmacy, University of Michigan, Ann Arbor, Michigan 48109-1065, USA \\ ${ }^{2}$ School of Biochemistry and Immunology, Trinity College Dublin, Dublin 2, Ireland
}

\begin{abstract}
The eukaryotic tRNA-guanine transglycosylase (TGT) has been reported to exist as a heterodimer, in contrast to the homodimeric eubacterial TGT. While ubiquitin-specific protease 14 (USP14) has been proposed to act as a regulatory subunit of the eukaryotic TGT, the mouse TGT has recently been shown to be a queuine tRNA-ribosyltransferase 1 (QTRT1, eubacterial TGT homolog)•queuine tRNA-ribosyltransferase domain-containing 1 (QTRTD1) heterodimer. We find that human QTRTD1 (hQTRTD1) co-purifies with polyhistidine-tagged human QTRT1 (ht-hQTRT1) via Ni ${ }^{2+}$ affinity chromatography. Cross-linking experiments, mass spectrometry, and size exclusion chromatography results are consistent with the two proteins existing as a heterodimer. We have not been able to observe co-purification and/or association between hQTRT1 and USP14 when coexpressed in Escherichia coli. More importantly, under our experimental conditions, the transglycosylase activity of hQTRT1 is only observed when hQTRT1 and hQTRTD1 have been co-expressed and co-purified. Kinetic characterization of the human TGT (hQTRT1•hQTRTD1) using human tRNA ${ }^{\text {Tyr }}$ and guanine shows catalytic efficiency $\left(k_{\text {cat }} / K_{M}\right)$ similar to that of the $E$. coli TGT. Furthermore, site-directed mutagenesis confirms that the hQTRT1 subunit is responsible for the transglycosylase activity. Taken together, these results indicate that the human TGT is composed of a catalytic subunit, hQTRT1, and hQTRTD1, not USP14. hQTRTD1 has been implicated as the salvage enzyme that generates free queuine from QMP. Work is ongoing in our laboratory to confirm this activity.
\end{abstract}

Keywords: tRNA-guanine transglycosylase; queuine tRNA-ribosyltransferase 1; queuine tRNA-ribosyltransferase domaincontaining 1; queuine; heterodimeric

\section{INTRODUCTION}

Of the $\sim 100$ tRNA modifications, queuine $\{\mathrm{Q} ; 7-[(4,5-c i s-$ dihydroxy-2-cyclopenten-1-yl) amino] methyl-7-deazaguanine is one of the most complicated forms that have been identified thus far. In contrast to eubacteria, eukaryotes

Abbreviations: Q, queuine; preQ, 7-aminomethyl-7-deazaguanine; preQ 0 , 7-cyano-7-deazaguanine; TGT, tRNA-guanine transglycosylase; QTRT1, queuine tRNA-ribosyltransferase 1; USP14, ubiquitin-specific protease 14; QTRTD1, queuine tRNA-ribosyltransferase domain-containing 1; DTT, dithiothreitiol; TAE, Tris-acetate-EDTA; HEPES, hydroxyethylpiperazineethylsulfonate; Tris- $\mathrm{HCl}$, tris(hydroxymethyl) aminomethane hydrochloride; DMS, dimethyl suberimidate; PMSF, phenylmethylsulfonyl fluoride; SDS, sodium dodecyl sulfate; PAGE, polyacrylamide gel electrophoresis; TCA, trichloroacetic acid; TEA, triethanolamine; MALDI, matrix-assisted laser desorption/ionization; TOF, time-of-flight.

Reprint requests to: George A. Garcia, Department of Medicinal Chemistry, College of Pharmacy, University of Michigan, Ann Arbor, MI 48109-1065, USA; e-mail: gagarcia@umich.edu; fax: (734) 647-8430.

Article published online ahead of print. Article and publication date are at http://www.rnajournal.org/cgi/doi/10.1261/rna.1997610. cannot synthesize queuine de novo and are required to obtain queuine from diet or gut flora as a nutrient factor (Reyniers et al. 1981). Although its physiological role is largely unclear, queuine modification of tRNA has been suggested to be involved in cell differentiation, proliferation, and response to oxidative stress (Langgut et al. 1993; Reisser et al. 1994; Pathak et al. 2007). In addition, it was reported that queuine- and tyrosine-deficient mice showed severe abnormalities such as labored breathing, seizures, and even death in some cases (Marks and Farkas 1997). Hypomodification of tRNA with respect to queuine has been related by clinical and in vitro studies to the malignant progression of several cancers (Emmerich et al. 1985; Huang et al. 1992; Baranowski et al. 1994; Pathak and Vinayak 2005). These observations have elicited an interest in acquiring a better understanding of the physiological roles of the queuine modification in eukaryotes.

Queuine modification of tRNA is conducted by tRNAguanine transglycosylase (TGT) (EC 2.4.2.29). TGT is considered 
to constitute a family of structurally homologous enzymes with differing substrate recognition across eukarya, eubacteria, and archea (Garcia and Kittendorf 2005). The transglycosylase reaction takes place at position 34 (anticodon wobble position) of tRNAs in eukaryotes and eubacteria, or position 15 (D loop) of tRNAs in archaea. TGT catalyzes the exchange of guanine for queuine in eukaryotes, $\mathrm{preQ}_{1}$ (7-aminomethyl-7-deazaguanine) in eubacteria, and preQ $_{0}$ (7-cyano-7-deazaguanine) in archaea. In eubacteria, $\mathrm{preQ}_{1}$ is further modified to queuine, and in archaea, $\mathrm{preQ}_{0}$ is modified to archaeosine. Eubacterial and eukaryl TGTs recognize tRNAs with the anticodon $\mathrm{G}_{34} \mathrm{U}_{35} \mathrm{~N}_{36}$, corresponding to the tRNAs that code for aspartic acid, asparagine, histidine, and tyrosine (Kasai et al. 1975). It has been proposed that the incorporation of queuine may play a role in affecting translation efficiency because queuine-modified tRNAs have been reported to recognize NAU codons more efficiently than NAC codons (Meier et al. 1985).

Although eubacterial TGTs have been intensively studied over the past two decades, the physical and kinetic properties of eukaryotic TGTs have yet to be fully understood. While the eukaryotic enzyme has been proposed to be a heterodimeric protein, differences in terms of the size and composition of the subunits have been reported in at least four different eukaryotes. When TGT was isolated from rabbit erythrocytes, 60 - and $43-\mathrm{kDa}$ subunits were observed (Howes and Farkas 1978). However, another study reported that the TGT from wheat germ is a homodimeric protein consisting of two 68-kDa subunits (Walden et al. 1982). Subsequent reports suggested that TGT isolated from bovine liver contains $66-$ and $32-\mathrm{kDa}$ subunits (Slany and Mueller 1995), while 60- and 34.5-kDa subunits were found in purified rat liver cell extract (Morris et al. 1995). In spite of these discrepancies, the general perception has been that the eukaryotic TGT exists as a heterodimer that is comprised of a $44-\mathrm{kDa}$ catalytic subunit and a putative $60-\mathrm{kDa}$ regulatory subunit. The queuine tRNA-ribosyltransferase 1 (qtrt1) gene was identified as the catalytic subunit due to a high degree of protein sequence homology $(\sim 40 \%)$ to the eubacterial TGT. The $60-\mathrm{kDa}$ subunit has no TGT-like catalytic activity and has been annotated as a member of the ubiquitin-specific protease family (USP14) (Deshpande et al. 1996; Deshpande and Katze 2001). Morris et al. (1995) reported that the $60-\mathrm{kDa}$ subunit of rat liver TGT (presumably USP14) is a protein kinase $\mathrm{C}(\mathrm{PKC})$ substrate and proposed that unphosphorylated TGT exists in a low-activity, dimeric state. The affinity between the two subunits reduces when the PKC-catalyzed phosphorylation takes place, and that results in the release of a highly active catalytic subunit (Morris et al. 1995). There has yet to be any detailed in vitro evidence supporting the USP14 regulation model. Interestingly, a very recent study revealed that in mouse, another TGT homolog, queuine tRNA-ribosyltransferase domain-containing 1 (QTRTD1), associates with queuine
tRNA-ribosyltransferase 1 (QTRT1), resulting in transglycosylase activity in vitro and mitochondrial localization in vivo (Boland et al. 2009), suggesting a new paradigm for the eukaryotic TGT.

In this study, molecular biology strategies were applied to generate recombinant human hQTRT1, hQTRTD1, and the heterodimeric hQTRT1·hQTRTD1 complex for detailed characterization. The physical and kinetic evidence obtained is consistent with a 1:1 heterodimeric complex for the human tRNA-guanine transglycosylase consisting of hQTRT1 and hQTRTD1. Furthermore, we find no evidence for the involvement of USP14.

\section{RESULTS}

\section{Eubacterial TGT homologs in Homo sapiens}

To investigate the subunit structure of the human TGT, we have cloned and expressed the genes for hQTRT1 and hQTRTD1. Figure 1 shows the protein sequence alignment of Escherichia coli TGT (ecTGT), hQTRT1, and hQTRTD1. Both human proteins share a high degree of homology with the E. coli enzyme $(39.1 \%$ and $20.1 \%$ sequence identities, respectively). ecTGT has been shown to be a zinc-binding protein (Chong et al. 1995; Xie et al. 2003). In both hQTRT1 and hQTRTD1, the four key residues responsible for $\mathrm{Zn}^{2+}$ binding (Cys302, Cys304, Cys307, and His333; E. coli numbering) are conserved. While three TGT activesite residues (Asp89, Asp143, and Asp264) are also conserved between ecTGT and hQTRT1, Cys, Ser, and Glu are found at the corresponding positions in hQTRTD1. Interestingly, each of these aspartates is conserved across all known TGT sequences among eubacteria, archaea, and eukarya. hQTRTD1 has been proposed to be a queuine salvage enzyme that catalyzes the hydrolysis of queuosine rather than transglycosylation (JR Katze, pers. comm.).

\section{Construction, overexpression, and purification of human TGT}

Polyhistidine-tagged hqtrt1 and unaltered hqtrtd1 genes were subcloned into a dual protein expression vector (pRSF-2 Ek/LIC) for co-expression trials. To eliminate any concerns regarding residual transglycosylase activity from the host cells and to enhance heterologous expression (i.e., rare codon usage), a tgt (-) E. coli strain containing a rare codon tRNA expression plasmid [E. coli K12 (DE3, $\Delta t g t)$-pRIPL] was utilized. During the expression trials, the addition of $\mathrm{Zn}^{2+}(100$ $\mu \mathrm{M})$ and low-temperature induction $\left(19^{\circ} \mathrm{C}\right)$ were found to be crucial for obtaining an optimal yield of active protein. hQTRTD1 co-purifies with polyhistidine-tagged hQTRT1 (ht-hQTRT1) via $\mathrm{Ni}^{2+}$ affinity chromatography. We also attempted to co-express ht-hQTRT1 and USP14, which was previously proposed to be a regulatory subunit of human TGT (i.e., an hQTRT1•USP14 heterodimer); however, we did not 


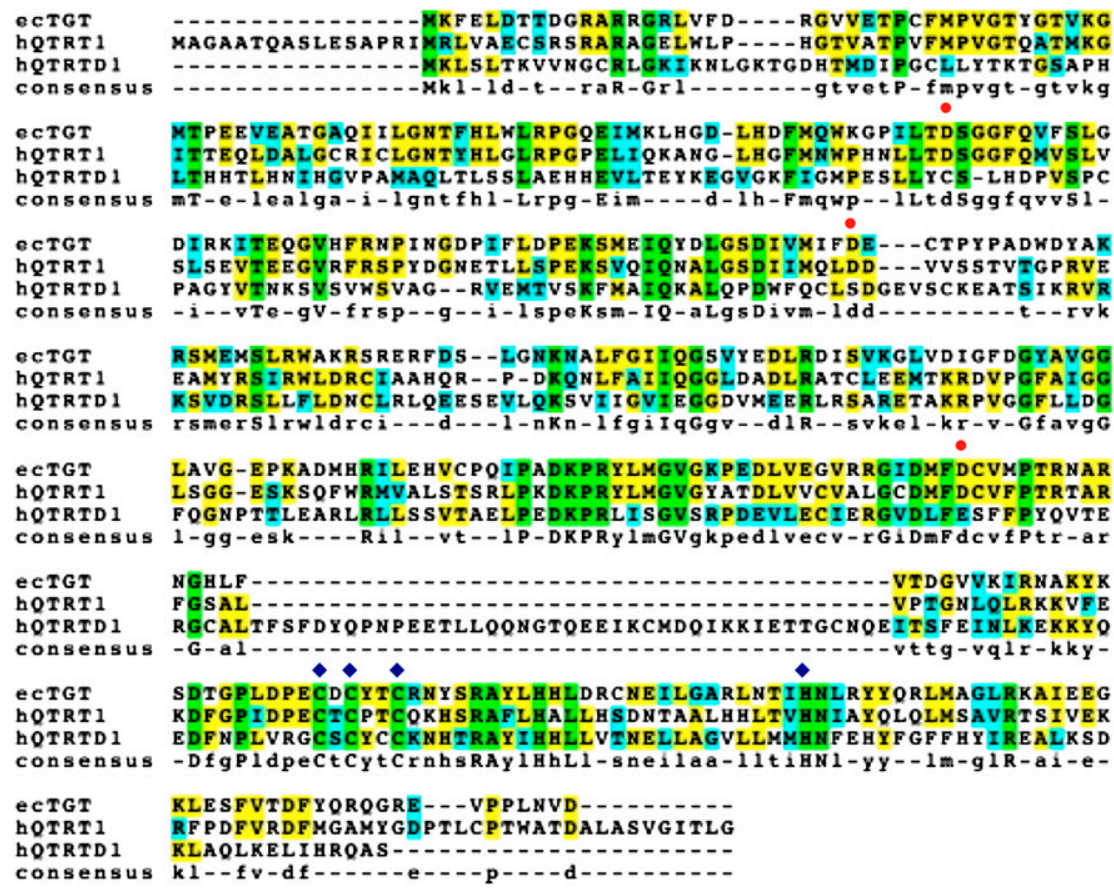

FIGURE 1. Protein sequence alignment of E. coli TGT (ecTGT), human QTRT1 (hQTRT1), and human QTRTD1 (hQTRTD1), conducted by CLUSTALW, Biology WorkBench 3.2. (Highlighted in green) Completely conserved residues; (highlighted in yellow) identical residues; (highlighted in cyan) similar residues. (Red dots) The three active-site aspartates (Asp 89, Asp 143, and Asp 264; E. coli numbering); (blue diamonds) the four key residues (Cys302, Cys304, Cys307, and His333) responsible for $\mathrm{Zn}^{2+}$ binding.

observe any co-purification between ht-hQTRT1 and USP14. The ht-hQTRT1·hQTRTD1 complex was further purified by size-exclusion chromatography. The size-exclusion chromatography also separated ht-hQTRT1•hQTRTD1 from "free" ht-hQTRT1 monomer (data not shown), which was also confirmed by sodium dodecyl sulfate-polyacrylamide gel electrophoresis (SDS-PAGE) analysis.

The purified human TGT (ht-hQTRT1•hQTRTD1) tends to precipitate from the storage buffer that we typically use for the E. coli enzyme $(25 \mathrm{mM}$ hydroxyethylpiperazine-ethylsulfonate [HEPES] at $\mathrm{pH} 7.3$ and $2 \mathrm{mM}$ dithiothreitiol [DTT]). We found that the addition of excipients $(100 \mathrm{mM} \mathrm{NaCl}$ and $50 \%[\mathrm{w} / \mathrm{v}]$ glycerol) stabilize the heterodimeric protein for storage. Densitometry analysis (data not shown) of denaturing SDS-PAGE (Fig. 2, lane 2) reveals that the ratio of ht-hQTRT1 to hQTRTD1 is $\sim 1: 1$. Unexpectedly, of the two protein bands detected, one (presumably ht-hQTRT1) migrates to a lower apparent molecular weight $(<45 \mathrm{kDa})$ than predicted from the amino acid sequence $(45.7 \mathrm{kDa})$. To confirm the identity of both bands, we performed mass spectrometry on peptides from tryptic digests of the bands excised from a denaturing gel (Michigan Proteome Core Facility). After mapping the observed peptide fragments against two protein databases, IPI Human and NCBI E. coli, our samples were confirmed to be hQTRT1 and hQTRTD1 (Supple- mental Figs. 1, 2; Supplemental Tables $1,2)$. Although the apparent molecular weight of ht-hQTRT1 on SDS-PAGE was less than the expected molecular weight, intact mass analysis reveled a molecular weight of $45.5 \mathrm{kDa}$ (Fig. 3A), confirming that the protein was intact. Interestingly, a small peak corresponding to a dimeric form of hQTRT1 $(90,931 \mathrm{kDa})$ was also seen in the mass spectrum (Fig. 3A), suggesting the formation of some amount of a homodimeric hQTRT1 under these conditions. The intact mass analysis of the purified ht-hQTRT1 •hQTRTD1 complex further revealed that both ht-hQTRT1 and hQTRTD1 are able to form some smaller amount of homodimeric species as well as the predominant heterodimer. As shown in Figure 3B, peak 91,290 kDa appears to be due to a homodimer of the protein giving rise to the peak at 45,510 kDa (ht-hQTRT1), and peak $94,724 \mathrm{kDa}$ seems to represent a homodimer of the monomer with a molecular weight of 47,355 kDa (hQTRTD1). Our observation of a peak corresponding to the hQTRTD1 homodimer is consistent with the report that the mouse QTRTD1 can self-associate weakly in vivo (Boland et al. 2009). Given that the hQTRTD1 homodimer is observed after $\mathrm{Ni}^{2+}$ affinity purification and that only ht-hQTRT1 is His-tagged, this suggests that there must be some form of a dynamic equilibrium existing between the dimeric forms, at least under these conditions. The most intense peak at $92,980 \mathrm{kDa}$ matches the molecular weight of a heterodimeric ht-hQTRT1•hQTRTD1, confirming that these two proteins associate in a 1:1 complex.

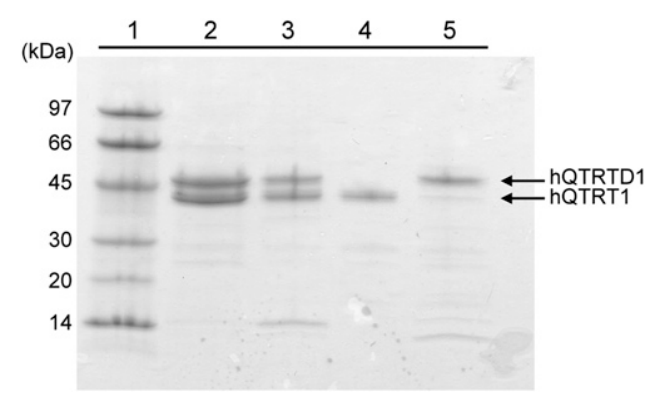

FIGURE 2. SDS-PAGE of various human TGT samples and subunits. (Lane 1) Low-molecular-weight standards (GE Healthcare). (Lane 2) Wild-type ht-hQTRT1•hQTRTD1. (Lane 3) ht-hQTRT1(D279N)• hQTRTD1. (Lane 4) ht-hQTRT1 monomer. (Lane 5) ht-hQTRTD1 monomer. The molecular weight of ht-hQTRT1 is predicted to be $\sim 45.7 \mathrm{kDa}$, while those of hQTRTD1 and ht-hQTRTD1 are $\sim 46.7 \mathrm{kDa}$ and $48.9 \mathrm{kDa}$, respectively. 

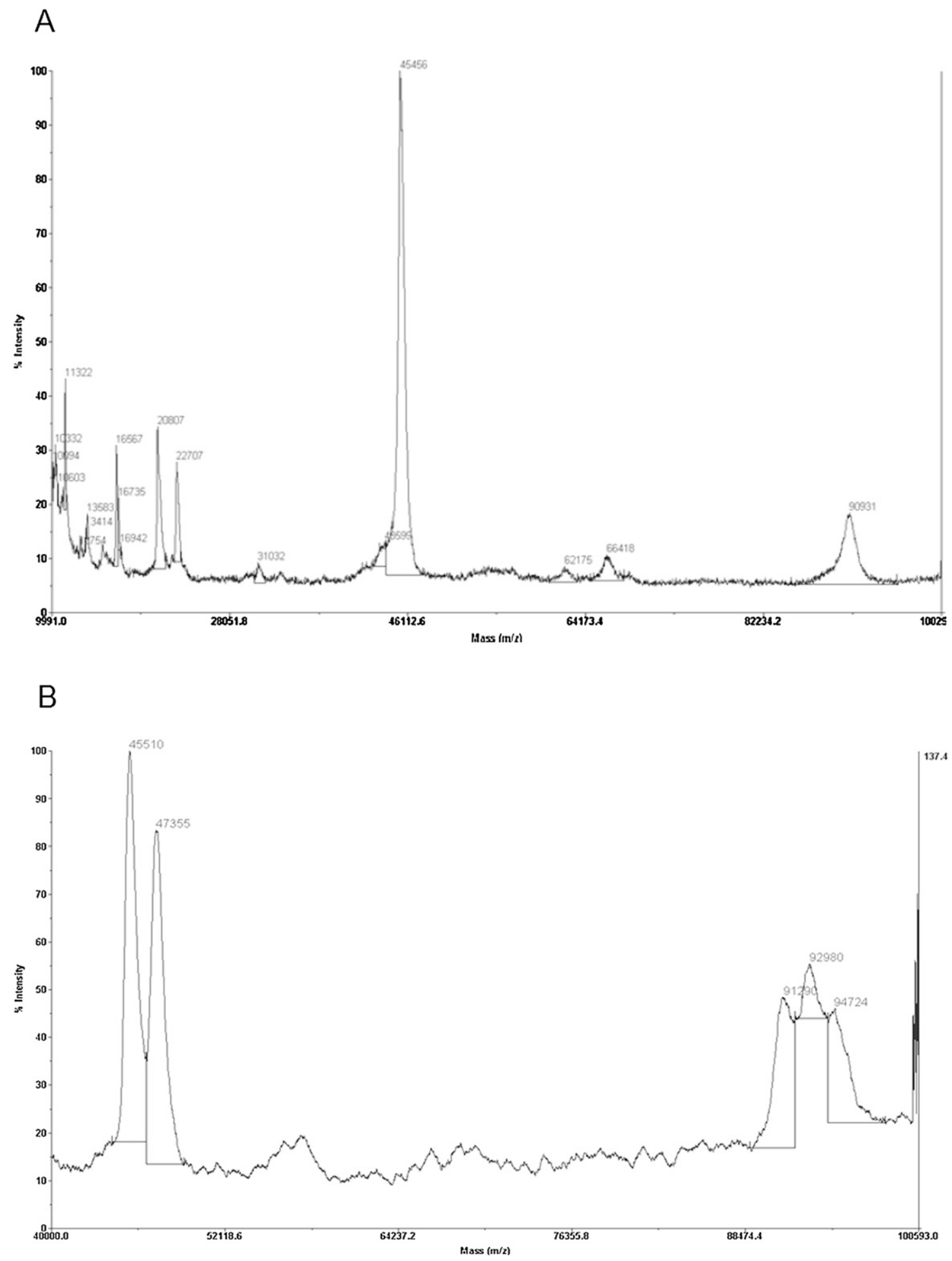

FIGURE 3. Intact mass analysis of $(A)$ ht-hQTRT1 and $(B)$ ht-hQTRT1·hQTRTD1.

Additionally, ht-hQTRT1 and ht-hQTRTD1 were also expressed and purified individually (as shown in Fig. 2, lanes 4,5). The recombinant ht-hQTRTD1 shows extremely low solubility during purification, most likely due to protein aggregation and/or misfolding. Using a chaperone-containing strain [E. coli BL21(DE3)-pGro7], significantly higher amounts of soluble ht-hQTRTD1, compared to several other expression systems, were obtained. However, the chaperones groES and groEL co-purified with ht-hQTRTD1 upon $\mathrm{Ni}^{2+}$ affinity chromatography. Anion-exchange chromatography 
was subsequently utilized to separate ht-hQTRTD1 from the chaperones.

To verify that the hQTRT1 subunit is responsible for the transglycosylase activity, a human TGT mutant [hthQTRT1(D279N)·hQTRTD1] was engineered via site-directed mutagenesis. The corresponding aspartate (D264) in the E. coli TGT has been shown to be critical for TGT activity but does not affect the gross structure or tRNA binding (Kittendorf et al. 2003; Xie et al. 2003). This heterodimeric mutant was then prepared in the same fashion as the wildtype enzyme. An example of the purified sample is shown in Figure 2, lane 3.

\section{Chemical cross-linking of ht-hQTRT1·hQTRTD1}

To probe the nature of the human TGT subunit association, chemical cross-linking was performed using a bisimidoester cross-linker, dimethyl suberimidate (DMS). As shown in Figure 4, in addition to the two individual subunits of the human TGT, a higher-molecular-weight protein band is indeed observed on SDS-PAGE (Fig. 4, lane 3 ), and it migrates to a position near the $97-\mathrm{kDa}$ marker (similar to the predicted molecular weight for the heterodimer), which suggests a 1:1 stoichiometry for the complex. While compelling, the SDS-PAGE analysis is only suggestive due to the low efficiency of cross-linking and the relatively low-molecular-weight resolution of the SDSPAGE. Therefore, the cross-linked protein band was excised and subjected to trypsin digestion and mass spectrometry to confirm the protein identities. Peptide fragments corresponding to both ht-hQTRT1 and hQTRTD1 were identified (Supplemental Fig. 3; Supplemental Table 3), consistent with a cross-linked TGT heterodimer.

\section{Kinetic analyses of human TGT with respect to human tRNA ${ }^{\mathrm{Tyr}}$ and guanine}

To kinetically characterize the human TGT transglycosylase activity, its cognate human tRNA ${ }^{\text {Tyr }}$ was first generated from in vitro transcription, purified via size-exclusion chromatography and verified by $2 \%$ agarose- Tris-acetate-EDTA (TAE) gels. The transglycosylase activity of the human TGT was examined by monitoring $\left[{ }^{14} \mathrm{C}\right]$-guanine incorporation

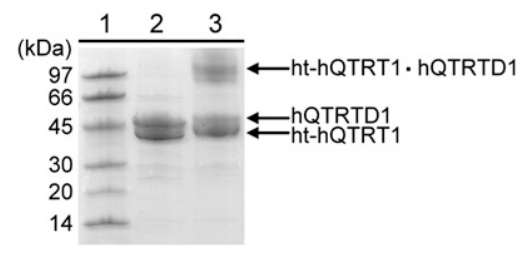

FIGURE 4. SDS-PAGE of ht-hQTRT1•hQTRTD1 cross-linking. (Lane 1) Low-molecular-weight standards (GE Healthcare). (Lane 2) ht-hQTRT1•hQTRTD1 control. (Lane 3) DMS-treated ht-hQTRT1• hQTRTD1. The expected molecular weight for a heterodimeric form of ht-hQTRT1 and hQTRTD1 is $\sim 93 \mathrm{kDa}$. into the human $\mathrm{tRNA}^{\mathrm{Tyr}}$, and kinetic parameters were determined by nonlinear fits to the Michaelis-Menten equation (Fig. 5). As shown in Table 1, tRNA ${ }^{\mathrm{Tyr}}$ and guanine exhibit very similar $K_{\mathrm{M}}$ values $(0.34 \mu \mathrm{M}, 0.41 \mu \mathrm{M}$, respectively) and, reassuringly, essentially identical $k_{\text {cat }}$ values $\left(5.60 \times 10^{-3} \mathrm{sec}^{-1}, 5.86 \times 10^{-3} \mathrm{sec}^{-1}\right.$, respectively). The catalytic efficiencies (as defined by $k_{\text {cat }} / K_{\mathrm{M}}$ ) of the human TGT with respect to tRNA ${ }^{\text {Tyr }}$ and guanine are very similar to those for the E. coli enzyme (Table 1).

In attempts to reconstitute ht-hQTRT1.hQTRTD1 from individually prepared ht-hQTRT1 and ht-hQTRTD1, we observed only very low levels of transglycosylase activity. Unfortunately, the magnitude of the activity was significantly less than that for the co-expressed and purified hthQTRT1-hQTRTD1 complex, and the data did not exhibit linearity over time. Neither ht-hQTRT1 nor ht-hQTRTD1 monomers are able to incorporate $\left[{ }^{14} \mathrm{C}\right]$-guanine into the human tRNA ${ }^{\text {Tyr }}$ (Fig. 6). Kinetic assays also showed that the ht-hQTRT1(D279N)-hQTRTD1 mutant exhibits no detectable transglycosylase activity (Fig. 6).

\section{DISCUSSION}

The general perception that eukaryotic TGTs exist as dimeric proteins has been based on observations of TGTs isolated from at least four different eukaryotes-rabbit erythrocytes (Howes and Farkas 1978); wheat germ (Walden et al. 1982); rat liver (Morris et al. 1995); and bovine liver (Slany and Mueller 1995). Protein sequence homology of QTRT1 to the eubacterial TGT, along with co-purification studies, led to the proposal that the eukaryl TGT was a heterodimer of QTRT1 and ubiquitin-specific protease 14 (USP14). It was hypothesized that QTRT1 was responsible for the transglycosylase activity, whereas USP14 regulated the activity of QTRT1 in response to phosphorylation by protein kinase C (PKC) (Langgut and Reisser 1995; Morris et al. 1995; Deshpande et al. 1996). Other than the co-purification of QTRT1 and USP14 reported previously, there have not been any rigorous in vitro experiments to support this hypothesis.

To elucidate the subunit structure of the human TGT, significant efforts have been made to obtain soluble and active hQTRT1 in our laboratory. However, transglycosylase activity has not been observed, even when the protein was co-expressed in a construct containing both hQTRT1 and its proposed protein partner, USP14. A recent study revealed that the mouse QTRT1 and QTRTD1 co-localize in mitochondria, suggesting the formation of a heterodimeric TGT complex between these two proteins (Boland et al. 2009). Additionally, they reported that transglycosylase activity was observed in vitro only when both subunits were present. Sequence analysis shows the high homology between hQTRT1 and hQTRTD1, especially in the $\mathrm{C}$-terminal domain. Based on the conservation of amino acid residues and tertiary structure prediction, both proteins 
A

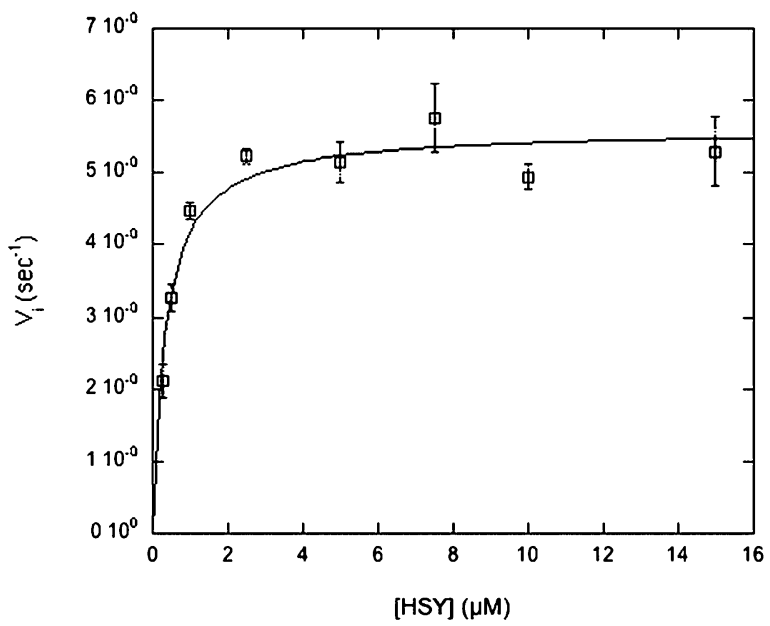

B

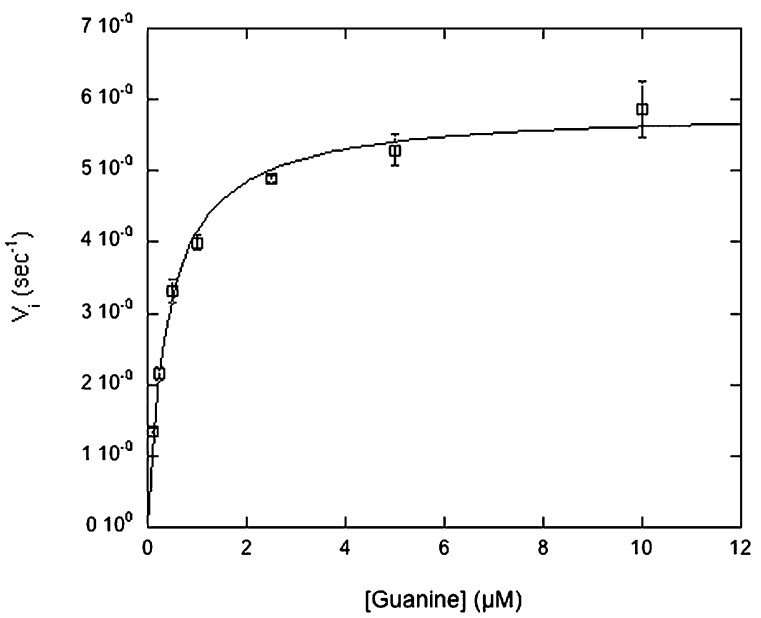

FIGURE 5. Kinetic characterization of $(A)$ human $\mathrm{tRNA}^{\mathrm{Tyr}}$ and $(B)$ guanine with human TGT (co-expressed, co-purified hthQTRT1•hQTRTD1).

most likely share the same $(\beta / \alpha)_{8}$ TIM-barrel scaffold with the eubacterial TGT, revealed by the crystal structure of Zymomonas mobilis TGT (Romier et al. 1996; Boland et al. 2009). Therefore, we elected to attempt co-expression of the human counterparts of these two proteins. Coexpression was successful, and all of the physical evidence (co-purification, chemical cross-linking, mass spectrometry) that we have obtained is consistent with the human TGT not only existing as a heterodimer of hQTRT1•hQTRTD1, but that the heterodimer is a 1:1 complex.

Our kinetic studies confirm that the transglycosylase activity of the human TGT comes from the hQTRT1• hQTRTD1 heterodimer and that neither hQTRT1 nor hQTRTD1 monomers exhibit any transglycosylase activity. The absence of any activity for the individual subunits also supports the idea that the homodimers we observed in the mass spectrometry studies likely have no physiological relevance as they would not have any activity even if they do exist in vivo. The human TGT exhibits kinetic parameters with respect to guanine and its cognate human tRNA $^{\text {Tyr }}$ that are essentially identical to those of the E. coli TGT. The sub-micromolar $K_{M}$ for guanine that we have observed suggests that the natural substrate, queuine, would likely have an even smaller $K_{\mathrm{M}}$ (due to the likely additional binding interactions with the dihydroxycyclopentenylamine moiety). In various eukaryotic tissues, the physiological queuine content is generally estimated to be in the low nanomolar range (e.g., $~ 3.6 \mathrm{nM}$ in human milk) (Katze et al. 1982). Given the low concentration of free queuine in vivo, this postulated high affinity of the human TGT for queuine seems reasonable. Kinetic studies of the human TGT and queuine are currently under way in our laboratory to confirm this and to gain further insight into the substrate specificity of the human TGT.
Our initial observations do not necessarily conflict with the previous proposal that USP14 regulates the transglycosylase activity of hQTRT1 in a protein kinase C (PKC)-dependent manner (Morris et al. 1995). Since hQTRT1 and hQTRTD1 are very similar in size, it is possible that in those previous studies they were not resolved as two distinct bands on SDS-PAGE. If so, USP14 could possibly bind to and regulate the heterodimer, consistent with their observation of $43-\mathrm{kDa}$ (presumably unresolved TGT subunits) and $60-\mathrm{kDa}$ bands on SDS-PAGE. However, we have seen no association of hQTRT1 and USP14, and in preliminary studies, we observed that the transglycosylase activity of hthQTRT1•hQTRTD1 is essentially unaffected by the presence of USP14, PKC/ATP, or alkaline phosphatase (data not shown). Further studies need to be conducted to absolutely confirm these observations, but at present we have no evidence supporting the USP14 regulation model.

TABLE 1. Kinetic parameters for human TGT and E. coli TGT with respect to their cognate $t R N A^{\mathrm{Tyr}}$ and guanine

\begin{tabular}{lccc}
\hline Kinetics & $\begin{array}{c}K_{\mathrm{M}}^{\mathrm{a}} \\
(\mu \mathrm{M})\end{array}$ & $\begin{array}{c}k_{\mathrm{cat}}^{\mathrm{a}} \\
\left(10^{-3} \mathrm{sec}^{-1}\right)\end{array}$ & $\begin{array}{c}k_{\mathrm{cat}} / K_{\mathrm{M}}^{\mathrm{a}, \mathrm{b}} \\
\left(10^{-3} \mathrm{sec}^{-1} \mu \mathrm{M}^{-1}\right)\end{array}$ \\
\hline tRNA & & & \\
$\quad$ Human TGT & $0.34( \pm 0.04)$ & $5.60( \pm 0.13)$ & $16.5( \pm 1.9)$ \\
$\quad \begin{array}{l}\text { E. coli TGT } \\
\text { Guanine }\end{array}$ & $0.12( \pm 0.04)$ & $1.21( \pm 0.07)$ & $10.1( \pm 3.4)$ \\
$\quad$ Human TGT & $0.41( \pm 0.03)$ & $5.86( \pm 0.10)$ & $14.2( \pm 0.9)$ \\
E. coli TGT & $0.10( \pm 0.03)$ & $1.21( \pm 0.07)$ & $12.1( \pm 3.7)$ \\
\hline
\end{tabular}

${ }^{\text {a }}$ Standard errors are in parentheses.

${ }^{\mathrm{b}}$ Derived from fit to the following equation: $V_{i}=\left(\frac{k_{\mathrm{cat}}}{K_{\mathrm{M}}}[S] / 1+\frac{K_{\mathrm{M}}}{[S]}\right)$. ${ }^{\mathrm{c}}$ From Kittendorf et al. (2001). 


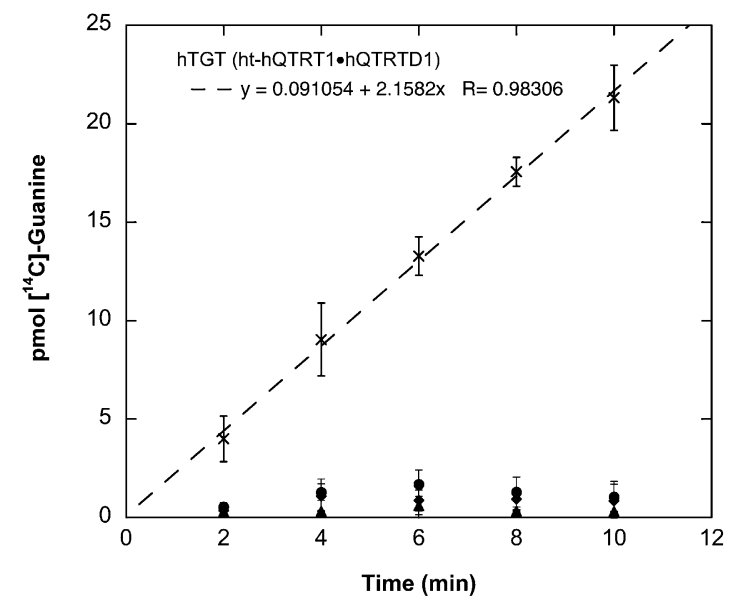

FIGURE 6. $\left[{ }^{14} \mathrm{C}\right]$-Guanine incorporated over time in human tRNA ${ }^{\mathrm{Tyr}}$ in the presence of (crosses) wild-type human TGT (ht-hQTRT1• hQTRTD1), (circles) mutant TGT [ht-hQTRT1(D279N)•hQTRTD1], (triangles) QTRT1 monomer, and (squares) hQTRTD1 monomers. Only the wild-type human TGT heterodimer shows an initial velocity (2.16 $\mathrm{pmol} / \mathrm{min}, R=0.9831)$. The mutant heterodimer, hQTRT1, and hQTRTD1 monomers did not exhibit any incorporation of $\left[{ }^{14} \mathrm{C}\right]$-guanine into tRNA ${ }^{\mathrm{Tyr}}$.

To determine which subunit (hQTRT1 or hQTRTD1) is actually responsible for the transglycosylase activity, two human TGT mutants, ht-hQTRT1(D279N)•hQTRTD1 and ht-hQTRT1•hQTRTD1(E272Q), were expressed and purified. The corresponding residue, aspartate 264, in the E. coli TGT is the nucleophilic catalyst that forms the covalent RNA-TGT intermediate (Kittendorf et al. 2003; Xie et al. 2003; Garcia et al. 2009). Mutation to anything other than glutamate yields catalytically inactive protein that is structurally unaltered (i.e., it folds correctly and binds, noncovalently to tRNA). As mentioned previously, in contrast to active-site aspartate 279 in hQTRT1, glutamate 272 is found at the corresponding position in hQTRTD1. Unexpectedly, when purifying the ht-hQTRT1·hQTRTD1(E272Q) mutant via $\mathrm{Ni}^{2+}$ affinity chromatography, we experienced a significant loss of the hQTRTD1 subunit, which resulted in a mixture of heterodimer and monomeric ht-hQTRT1. Evidently, the mutation somehow reduces the affinity of the subunits in the heterodimer. The consequence is that we were unable to test the transglycosylase activity of the QTRTD1 mutant heterodimer.

Our attempts to reconstitute the wild-type heterodimer from individually expressed and purified subunits gave inconclusive results. It is possible that the N-terminal Histag on hQTRTD1 (used for purification and not present in the co-expressed protein) may impair the interaction with ht-hQTRT1. The His-tag on hQTRT1 does not appear to affect the association between ht-hQTRT1 and hQTRTD1, as both physical and kinetic evidence supports the formation of the heterodimer. An N-terminal His-tag has previously been shown to have no effect on the activity of the eubacterial TGT (Todorov et al. 2005). Our observation of an active dimeric human TGT is consistent with the crystallographic evidence derived from $Z$. mobilis TGT (Xie et al. 2003; Stengl et al. 2007), which indicates that the eubacterial TGT forms a homodimer. While one subunit is capable of recognizing the tRNA anticodon loop and performs the transglycosylase reaction, the other one assists in maintaining the proper orientation of bound tRNA.

Unlike eubacteria, which biosynthesize queuine from its precursor preQ $_{1}$, eukaryotes are incapable of synthesizing queuine de novo and have to obtain free queuine from diet. Almost three decades ago, Reyniers et al. (1981) reported that germ-free mice could utilize dietary queuosine-containing tRNA (Q-tRNA) to produce free queuine, suggesting that there is a salvage system existing in eukarya to compensate for the inability to synthesize queuine. Subsequent studies showed that monkey kidney epithelial cells are able to uptake queuine from degraded Q-tRNA and that the substrate for this salvage activity is queuosine $5^{\prime}$-monophosphate (QMP) (Gunduz and Katze 1982, 1984). By studying partially purified extracts from two eukaryotic algae, Chlorella pyrenoidosa and Chlamydomonas reinhardtii, the same group later reported similar observations with the exception that the nucleoside queuosine seems to be the substrate in these plant cells rather than QMP (Kirtland et al. 1988). Due to its high homology with QTRT1, QTRTD1 has been suggested to be involved in this salvage pathway (Vandenbergh et al. 2003), although in vitro evidence supporting this hypothesis has not yet been reported. It was observed that in every eukaryote that contains the qtrt1 gene, a corresponding qtrtd 1 gene is found (JR Katze, pers. comm.). Assuming that QTRTD1 is confirmed to be the queuine salvage enzyme, the fact that it forms the heterodimer with QTRT1, which catalyzes queuine transglycosylation, is evolutionarily intriguing. As mentioned previously, eukarya lack a queuine biosynthesis pathway. To ensure a consistent supply of queuine in vivo, it seems reasonable for the eukaryotic TGT to evolve into a heterodimer, where QTRTD1 is capable of assisting in tRNA binding and, more importantly, generating the heterocyclic substrate queuine for QTRT1. Our laboratory is currently studying hQTRTD1 to confirm this queuine salvage activity.

In summary, all of the physical and kinetic evidence in this study is most consistent with a new paradigm for the human TGT. Co-purification through two different chromatographies, mass spectrometry, and chemical crosslinking confirm a 1:1 association between ht-hQTRT1 and hQTRTD1. Transglycosylation activity was only seen for the ht-hQTRT1·hQTRTD1 heterodimer, and hQTRT1 was shown to be responsible for this activity via specific mutagenesis of a key catalytic residue. Based on these results, we conclude that the functional human TGT is a heterodimeric protein, which consists of a transglycosylase subunit, hQTRT1, and hQTRTD1 (with the likely role of queuine salvage from QMP), and no evidence supporting the previous proposed involvement of USP14 was found. 


\section{MATERIALS AND METHODS}

\section{Reagents}

Unless otherwise specified, all reagents were ordered from SigmaAldrich. DNA oligonucleotides, agarose, dithiothreitol (DTT), T4 DNA ligase, and DNA ladders were ordered from Invitrogen. The human tRNA $^{\text {Tyr }}$ gene was synthesized by the Midland Certified Reagent Company. All restriction enzymes and Vent DNA polymerase were ordered from New England Biolabs. The ribonucleic acid triphosphates (NTPs), pyrophosphatase, and kanamycin sulfate were ordered from Roche Applied Sciences. The deoxyribonucleic acid triphosphates (dNTPs) were ordered from Promega. Low-melting Seaplaque agarose was ordered from Lonza. Gelase Enzyme Prep and Scriptguard RNase Inhibitor were ordered from Epicentre. Epicurian coli XL2-Blue ultracompetent cells were ordered from Stratagene, TG2 cells were from a laboratory stock, and BL21-CodonPlus (DE3)-RIPL cells were from Novagen. His•Bind resin and lysonase bioprocessing reagent were also purchased from Novagen. The QIAPrep Spin Miniprep and Maxiprep Kits were ordered from QIAGEN. Precast PhastGels and SDS buffer strips were from VWR. Bradford reagent was from Bio-Rad. Whatman GF/C Glass Microfibre Filters, Amicon Ultra Centrifugal Filter Devices, carbenicillin, and all bacterial media components were ordered from Fisher. $\left[8-{ }^{14} \mathrm{C}\right]$ Guanine $(50-60$ $\mathrm{mCi} / \mathrm{mmol}$ ) was ordered from Moravek Biochemicals. T7 RNA polymerase was isolated from E. coli BL21(DE3) pLysS cells harboring the plasmid pRC9 via minor modifications of the procedure described in the literature (He et al. 1997).

\section{Preparation and purification of tRNA}

The commercially synthesized DNA oligomer containing the human tRNA ${ }^{\mathrm{Tyr}}$ gene (5'-gagaagctttaatacgactcactataggccttcgatagct cagttggtagagcggaggactgtagatccttaggtcgctggttcgaatccggctcgaaggaccagga attcgag- $3^{\prime}$, where the tRNA ${ }^{\text {Tyr }}$ gene is underlined) was amplified by polymerase chain reaction (PCR) under the following conditions: primers (20 pmol each), tRNA ${ }^{\mathrm{Tyr}}$ gene $(500 \mathrm{ng}), \mathrm{Mg}^{2+}(2 \mathrm{mM})$, dNTPs $(0.5 \mathrm{mM}$ each), ThermolPol buffer $(1 \times)$, Vent DNA polymerase $(2 \mathrm{U})$, in a final volume of $50 \mu \mathrm{L}$. The sample was treated with 30 PCR cycles of the following sequence: $94^{\circ} \mathrm{C}(1 \mathrm{~min}), 60^{\circ} \mathrm{C}$ (30 sec), and $72^{\circ} \mathrm{C}(2 \mathrm{~min})$. Following a double restriction enzyme digestion with EcoRI and HindIII (20 U each, $20-\mu \mathrm{L}$ reaction) for $1 \mathrm{~h}$ at $37^{\circ} \mathrm{C}$, the PCR product and vector pTZ18U $\mathrm{U}^{\text {Amp }}$ were gelpurified from Seaplaque agarose with Gelase according to the vendor's protocol. The $\mathrm{tRNA}^{\mathrm{Tyr}}$ gene was then ligated into pTZ18U ${ }^{\text {Amp }}$ (5:1 volume ratio, $20-\mu \mathrm{L}$ reaction) following overnight incubation with T4 DNA ligase $(2 \mathrm{U})$ at $16^{\circ}-17^{\circ} \mathrm{C}$. The ligated sample $(10 \mu \mathrm{L})$ was transformed into $100 \mu \mathrm{L}$ of Epicurian coli XL2-Blue ultracompetent cells according to the Stratagene protocol. Cells were grown overnight at $37^{\circ} \mathrm{C}$ on L-Amp plates $(50 \mu \mathrm{g} / \mathrm{mL}$ ampicillin). Individual colonies were isolated, and $3 \mathrm{~mL}$ of $2 \mathrm{xTY}$ (16 $\mathrm{g}$ of bactotryptone, $10 \mathrm{~g}$ of yeast extract, $5 \mathrm{~g}$ of $\mathrm{NaCl} / \mathrm{L}$ of water with $50 \mu \mathrm{g} / \mathrm{mL}$ ampicillin) liquid cultures were inoculated and grown overnight at $37^{\circ} \mathrm{C}$ with shaking. The plasmids were isolated via miniprep, and the tRNA ${ }^{\mathrm{Tyr}}$ gene sequence was confirmed with DNA sequencing (University of Michigan DNA Sequencing Core Facilities). A plasmid containing the $\mathrm{tRNA}^{\mathrm{Tyr}}$ gene was then re-transformed into TG2-competent cells for further plasmid preparation.
To obtain the human tRNA ${ }^{\mathrm{Tyr}}$ for kinetic characterization of the human TGT, the plasmid containing the $\mathrm{tRNA}^{\text {Tyr }}$ gene $\left(p t R N A^{T y r}\right.$ ) was first linearized at the end of the tRNA ${ }^{\text {Tyr }}$ sequence with the restriction enzyme BstNI $(50 \mathrm{U}, 200-\mu \mathrm{L}$ reaction) for at least $4 \mathrm{~h}$. The digested ptRNA ${ }^{\mathrm{Tyr}}$ was ethanol-precipitated overnight at $-20^{\circ} \mathrm{C}$ and then pelleted by centrifugation $(13,000 \mathrm{rpm}$, $15 \mathrm{~min})$. The $\mathrm{tRNA}^{\mathrm{Tyr}}$ was subsequently generated by in vitro transcription. In vitro $0.5-\mathrm{mL}$ transcription conditions were as follows: ptRNA ${ }^{\mathrm{Tyr}}$ template (re-suspended in $325 \mu \mathrm{L}$ of deionized water), transcription buffer ( $4 \mathrm{mM}$ tris(hydroxymethyl) aminomethane hydrochloride [Tris- $\mathrm{HCl}$ ] at $\mathrm{pH} 8.0 ; 2 \mathrm{mM} \mathrm{MgCl}_{2}, 0.5$ mM DTT, $0.1 \mathrm{mM}$ spermidine), NTPs (4 mM each), T7 RNA polymerase $(250 \mathrm{nM})$, and RNase inhibitor (100 U). The reaction was incubated for $\sim 4 \mathrm{~h}$ at $37^{\circ} \mathrm{C}$, after which time white precipitates (magnesium pyrophosphate) were removed by centrifugation $(13,000 \mathrm{rpm}, 5 \mathrm{~min})$. The tRNA transcript was ethanolprecipitated at $-20^{\circ} \mathrm{C}$ and then pelleted by centrifugation $\left(20,000 \mathrm{~g}, 30 \mathrm{~min}, 4^{\circ} \mathrm{C}\right)$. Purification of the tRNA transcript was achieved by size exclusion chromatography using two Superose 12 HR 10/30 columns (GE Healthcare) connected in tandem. The running buffer, which is also used for tRNA storage, contains $10 \mathrm{mM}$ HEPES (pH 7.3) and $1 \mathrm{mM} \mathrm{MgCl}_{2}$. The concentration of the tRNA was determined from the extinction coefficient at $260 \mathrm{~nm}\left(\varepsilon_{260}=\right.$ $0.660 \mathrm{~A}_{260} \mathrm{~cm}^{-1} \mu \mathrm{M}^{-1}$, corrected for hypochromicity) (Curnow et al. 1993) using a Cary UV-Visible Spectrophotometer (Varian).

\section{Construction and cloning of human TGT}

To ensure a higher efficiency of heterologous expression in an $E$. coli host, we took advantage of codon degeneracy and chemically synthesized the first 104 bases of the human qtrt1 gene (hqtrt1) with codons optimized for expression in $E$. coli. The fragment was then appended to the PCR product from the EST clone BE797707 (Incyte Genomics) through KpnI digestion and subsequent ligation. The usp14 gene was acquired from the EST clone BC003556 (Incyte Genomics) and amplified by PCR. The human qtrtd1 gene ( $h$ qtrtd1, cloned in pET28a) was kindly provided by Jon Katze from the University of Tennessee, Memphis.

The hqtrt1 and usp14 genes were subcloned into a dual protein expression vector, pRSF-2 Ek/LIC (Ligation-Independent Cloning), following the vendor's protocol (Novagen) to obtain the construct of pht-hQTRT1-USP14. The construct of pht-hQTRT1•hQTRTD1 was generated by replacing usp14 with hqtrtdl through double restriction enzyme digestion with NdeI and HindIII followed by the general laboratory ligation protocol described previously. The constructs of pht-hQTRT1(D279N)• hQTRTD1 and pht-hQTRT1•hQTRTD1(E272Q) mutants were generated from the wild-type pht-hQTRT1•hQTRTD1 using QuikChange site-directed mutagenesis (Stratagene). Briefly, $30-\mu \mathrm{L}$ reactions containing $500 \mathrm{ng}$ of plasmid pht-hQTRT1 • hQTRTD1, $333 \mathrm{nmol}$ of each of the respective mutagenic primers synthesized by Invitrogen [for pht-hQTRT1(D279N)•hQTRTD1, fwd: 5' -gctcttggatgtgacatgttcaactgcgtcttccccacacggacag-3'; rev: 5' ctgtccgtgtggggaagacgcagttgaacatgtcacatccaagagc- $3^{\prime}$; and for phthQTRT1•hQTRTD1(E272Q), fwd: gaaagaggagtggacttatttcagagtttttt cccttatcaagtaac; rev: $5^{\prime}$-gttacttgataagggaaaaaactctgaaataagtccactcctc $\mathrm{tttc}], \mathrm{Mg}^{2+}$ (2 mM), dNTPs (0.25 mM each), ThermolPol buffer $(1 \times)$, and 2 units of Vent DNA polymerase were subjected to 30 PCR cycles of the following temperature sequence: $94^{\circ} \mathrm{C}(30 \mathrm{sec})$, $50^{\circ} \mathrm{C}(1 \mathrm{~min})$, and $72^{\circ} \mathrm{C}(6.5 \mathrm{~min})$. Following digestion with 20 units 
of DpnI for $1 \mathrm{~h}, 10 \mu \mathrm{L}$ of the PCR product was transformed into $100 \mu \mathrm{L}$ of Epicurian coli XL2-Blue ultracompetent cells according to the vendor's protocol (Stratagene). Cells were grown overnight at $37^{\circ} \mathrm{C}$ on L-Agar plates containing $50 \mu \mathrm{g} / \mathrm{mL}$ kanamycin and $30 \mu \mathrm{g} / \mathrm{mL}$ chloramphenicol. Individual colonies were isolated, and $3 \mathrm{~mL}$ of $2 \mathrm{xTY}$ (with $50 \mu \mathrm{g} / \mathrm{mL}$ kanamycin and $30 \mu \mathrm{g} / \mathrm{mL}$ chloramphenicol) liquid cultures were inoculated at $37^{\circ} \mathrm{C}$ with shaking. The plasmids were isolated via miniprep, and the tgt mutant genes were confirmed with DNA sequencing.

\section{Preparation and purification of human TGT}

Plasmids containing the ht-hQTRT1•hQTRTD1 and hthQTRT1(D279N)•hQTRTD1 genes were transformed into $200 \mu \mathrm{L}$ of E. coli K12 (DE3, $\Delta t g t$ )-pRIPL competent cells for expression trials. In brief, cells were grown in 1-2 L of $2 x T Y$ liquid cultures containing $100 \mu \mathrm{M} \mathrm{ZnSO}_{4}$ at $37^{\circ} \mathrm{C}$ with vigorous shaking until the $\mathrm{OD}_{600}$ value reached $\sim 0.6$. The cultures were transferred to $19^{\circ} \mathrm{C}$ for a 30 -min incubation, and the protein was then induced by the addition of IPTG to a final concentration of $1 \mathrm{mM}$. The cultures were allowed to incubate for additional $24-30 \mathrm{~h}$ at $19^{\circ} \mathrm{C}$, after which time the cells were harvested by centrifugation $\left(6000 \mathrm{~g}, 15 \mathrm{~min}, 4^{\circ} \mathrm{C}\right)$. The cell pellets from each $500-\mathrm{mL}$ culture were re-suspended in $10 \mathrm{~mL}$ of $\mathrm{Ni}^{2+}$-NTA bind buffer ( $300 \mathrm{mM} \mathrm{NaCl}, 50 \mathrm{mM} \mathrm{NaH}_{2} \mathrm{PO}_{4}, 10 \mathrm{mM}$ imidazole, at $\mathrm{pH}$ 8.0) containing $100 \mu \mathrm{M}$ phenylmethylsulfonyl fluoride (PMSF) and $10 \mu \mathrm{L}$ of lysonase. The cell suspensions were incubated for $20 \mathrm{~min}$ at room temperature and subjected to sonication (seven 15-sec pulses) on ice. The cellular debris was pelleted by centrifugation $\left(13,000 \mathrm{~g}, 30 \mathrm{~min}, 4^{\circ} \mathrm{C}\right)$.

All further purification steps were performed at $4^{\circ} \mathrm{C}$. The supernatants were sterile-filtered with $0.22-\mu \mathrm{m}$ syringe filters (Millipore) and incubated with $1 \mathrm{~mL}$ of His-Bind slurry with gentle shaking for $1 \mathrm{~h}$. Each supernatant-resin mixture was then applied to a column. Following the loading of supernatants, columns were washed with $4 \mathrm{~mL}$ of $\mathrm{Ni}^{2+}$-NTA wash buffer $(300$ $\mathrm{mM} \mathrm{NaCl}, 50 \mathrm{mM} \mathrm{NaH}_{2} \mathrm{PO}_{4}, 20 \mathrm{mM}$ imidazole, at $\mathrm{pH}$ 8.0) twice. The N-terminal polyhistidine-tagged proteins were eluted from each column with $2 \mathrm{~mL}$ of elute buffer $(300 \mathrm{mM} \mathrm{NaCl}, 50 \mathrm{mM}$ $\mathrm{NaH}_{2} \mathrm{PO}_{4}, 250 \mathrm{mM}$ imidazole, at $\mathrm{pH} 8.0$ ) and collected in $0.5-\mathrm{mL}$ fractions. The eluates were examined by SDS-PAGE, and fractions containing ht-hQTRT1•hQTRTD1 were combined. The enzyme samples were further applied to a HiPrep 16/60 Sephacryl S-200 HR (GE Healthcare) column, and the running buffer was $25 \mathrm{mM}$ HEPES ( $\mathrm{pH}$ 7.3) in the presence of $300 \mathrm{mM} \mathrm{NaCl}$ and $2 \mathrm{mM}$ DTT. Following the verification by SDS-PAGE, fractions containing our proteins of interest were combined and concentrated. Subsequently, the proteins were exchanged into the hTGT storage buffer: $25 \mathrm{mM}$ HEPES (pH 7.3), 2 mM DTT, $100 \mathrm{mM} \mathrm{NaCl}$, and $20 \%$ (w/v) glycerol using Amicon Ultra Centrifugal Filter Devices (10,000 MWCO) following vender protocols (the glycerol content was immediately brought to $50 \%[\mathrm{w} / \mathrm{v}]$ after the process of buffer exchange for storage). The final concentrations of hthQTRT1•hQTRTD1 and ht-hQTRT1(D279N)•hQTRTD1 were determined with the Bio-Rad Protein Assay Kit based on the Bradford assay using BSA standards. The proteins were stored in liquid $\mathrm{N}_{2}$ until needed. The ht-QTRT1 monomer was expressed in the same E. coli strain harboring plasmid pht-QTRT1-USP14, and then purified in the same fashion.

The ht-QTRTD1 monomer was expressed in an E. coli strain harboring a chaperone-containing plasmid, pGro7 (a pACYC derivative that contains two chaperones, groES and groEL; purchased from Takara Bio Inc.). Initially, pht-QTRTD1 was transformed into pGro7-containing BL21 (DE3) cells (from a laboratory stock). Subsequently, the clone containing phtQTRTD1 and pGro7 was expressed following the commercial protocol (Takara Bio Inc.). Briefly, in a 1-L culture containing $100 \mu \mathrm{M} \mathrm{ZnSO}_{4}$, chaperones (groES-groEL) were first induced by the addition of L-arabinose $(2 \mathrm{mg} / \mathrm{mL})$ for $\sim 2 \mathrm{~h}$ at $37^{\circ} \mathrm{C}$, until the culture reached an $\mathrm{OD}_{600}$ value of 0.4 to 0.6 . Subsequently, the culture was transferred for $30 \mathrm{~min}$ to $19^{\circ} \mathrm{C}$, followed by the addition of IPTG $(0.5 \mathrm{mM})$ to induce the expression of htQTRTD1. The induction was then carried out for $\sim 24 \mathrm{~h}$ at $19^{\circ} \mathrm{C}$, after which time the cells were harvested by centrifugation $(6000 \mathrm{~g}$, $15 \mathrm{~min}, 4^{\circ} \mathrm{C}$ ). The cell pellet from each $500-\mathrm{mL}$ culture was lysed as described previously followed by $\mathrm{Ni}^{2+}$ affinity purification with some modifications. In brief, the filtered supernatant obtained from cell lysates was incubated with $1 \mathrm{~mL}$ of His•Bind slurry and $10 \mathrm{mM}$ ATP with gentle shaking for $1 \mathrm{~h}$. The mixture was then applied to a column. Following the loading of supernatant, the column was washed twice with $4 \mathrm{~mL}$ of $\mathrm{Ni}^{2+}$-NTA wash buffer (300 mM NaCl, $50 \mathrm{mM} \mathrm{NaH}{ }_{2} \mathrm{PO}_{4}, 20 \mathrm{mM}$ imidazole, at $\mathrm{pH} 8.0$ ) containing $10 \mathrm{mM}$ ATP. Subsequently, ht-QTRTD1 was eluted from the column with $2 \mathrm{~mL}$ of elute buffer $(300 \mathrm{mM} \mathrm{NaCl}, 50$ $\mathrm{mM} \mathrm{NaH} \mathrm{PO}_{4}, 250 \mathrm{mM}$ imidazole, at $\mathrm{pH}$ 8.0) and collected in $0.5-\mathrm{mL}$ fractions. The eluates were verified by SDS-PAGE, and fractions containing ht-hQTRTD1 were combined. Further purification of ht-QTRTD1 was achieved by anion exchange chromatography (MonoQ HR 10/10 column; Pharmacia) with a binary elution gradient program. The two eluents were: (A) $25 \mathrm{mM}$ HEPES (pH 7.3), $2 \mathrm{mM}$ DTT, and $300 \mathrm{mM} \mathrm{NaCl}$; and (B) $25 \mathrm{mM}$ HEPES ( $\mathrm{pH}$ 7.3), $2 \mathrm{mM}$ DTT, and $1 \mathrm{M} \mathrm{NaCl}$. Following the verification by SDS-PAGE, fractions containing ht-QTRTD1 were combined and concentrated. Subsequently, the protein was exchanged into the hTGT storage buffer and stored in liquid $\mathrm{N}_{2}$ for further use as described above.

\section{Examination of the identity and integrity of human TGT}

The identity and integrity of the human TGT samples were examined by the Michigan Proteome Consortium (University of Michigan). In brief, ht-hQTRT1 and QTRTD1 were separated and stained on a denaturing SDS-PAGE gel. Following the excision of the protein bands, the in-gel samples were digested with trypsin and analyzed by matrix-assisted laser desorption/ionization (MALDI) time-of-flight (TOF) tandem mass spectrometry. The observed peptide fragments were then compared to the IPI human database, and the data were analyzed by Mascot and Protein Pilot to determine protein identity. Additionally, intact mass analyses were performed to confirm protein integrity, where the solution forms of purified ht-hQTRT1 and ht-hQTRT1•QTRTD1 were subjected to MALDI-TOF mass spectrometry.

\section{Chemical cross-linking of ht-hQTRT1-hQTRTD1}

Bisimidoester cross-linking was performed essentially as previously described (Garcia et al. 1993). Briefly, purified hthQTRT1•hQTRTD1 in $0.2 \mathrm{M}$ triethanolamine (TEA) buffer ( $\mathrm{pH}$ 8.0) was mixed with a fresh preparation of dimethylsuberimidate (in $0.2 \mathrm{M}$ TEA at $\mathrm{pH} 8.0$ ) to give a final concentration of $14 \mu \mathrm{M}$ 
ht-hQTRT1•hQTRTD1 and $20 \mathrm{mM}$ dimethylsuberimidate in a $10-\mu \mathrm{L}$ reaction. The reaction mixtures were incubated for $2 \mathrm{~h}$ at $25^{\circ} \mathrm{C}$, and the cross-linking products were then analyzed and visualized by SDS-PAGE. Additionally, the cross-linked protein band was excised and submitted to the Michigan Proteome Consortium for mass spectrometric analysis of protein identity.

\section{Activity screen and kinetic analyses}

Guanine exchange assays were conducted by monitoring the incorporation of radiolabeled substrate, $\left[8^{-14} \mathrm{C}\right]$ guanine, into the human tRNA ${ }^{\mathrm{Tyr}}$ using various human TGT samples (e.g., heterodimer, mutant, and individual monomers). In brief, kinetic assays were set up under the following conditions: tRNA ${ }^{\text {Tyr }}$ (various concentrations but fixed at $10 \mu \mathrm{M}$ for guanine kinetics), $\left[8-{ }^{14} \mathrm{C}\right]$ guanine $(57 \mathrm{mCi} / \mathrm{mmol}$, various concentrations but fixed at $20 \mu \mathrm{M}$ for tRNA kinetics), human TGT (100 nM), and HEPES reaction buffer (100 mM HEPES at $\mathrm{pH} 7.3 ; 20 \mathrm{mM} \mathrm{MgCl}_{2} ; 5 \mathrm{mM}$ DTT) to a final volume of $400 \mu \mathrm{L}$. The studies were performed in triplicate at saturating concentration of the other substrate. All samples were incubated at $37^{\circ} \mathrm{C}$ for purposes of equilibration before initiating the reaction with the addition of TGT. Aliquots $(70 \mu \mathrm{L})$ were removed every $2 \mathrm{~min}$ throughout the 10 -min time course and immediately quenched in $2.5 \mathrm{~mL}$ of $5 \%$ trichloroacetic acid (TCA) for $1 \mathrm{~h}$ before filtering on glass-fiber filters. Each filter was washed with three volumes of 5\% TCA and a final wash of ethanol to dry the filter. The samples were analyzed in a scintillation counter (Beckman) for radioactive decay, where counts were reported in DPM and later converted to picomoles of $\left[8^{-14} \mathrm{C}\right]$ guanine by the following conversion: pmol $=\mathrm{DPM} \times 0.0079$, for the $\left[8-{ }^{14} \mathrm{C}\right]$ guanine stock with a specific activity of $57 \mathrm{mCi} / \mathrm{mmol}$. To obtain steady-state kinetic parameters for the wild-type hthQTRT1•QTRTD1, initial velocities of guanine incorporation were determined by converting the slopes of these plots (in picomoles per minute) to units of second ${ }^{-1}$, taking into account the concentration of the enzyme and aliquot size. The individual data points from each trial were averaged, and the standard deviation was determined for each concentration of either $\mathrm{tRNA}^{\mathrm{Tyr}}$ or guanine. The average data points (with error bars representing their standard deviations) were plotted. However, all of the individual data points were fit via nonlinear regression to the Michaelis-Menten equation using Kaleidagraph (Abelbeck Software).

\section{SUPPLEMENTAL MATERIAL}

Mass spectrometric methodology and analyses (e.g., peptide fragments found and matched) with respect to the identification of ht-hQTRT1, hQTRTD1, and cross-linked ht-hQTRT1•hQTRTD1 can be found in the Supplemental Material at the following URL (http://sitemaker.umich.edu/garcia.pubs/files/ChenSuppInfo.pdf) and at http://www.rnajournal.org.

\section{ACKNOWLEDGMENTS}

We thank Professor Jon Katze (University of Tennessee, Memphis) for generously providing the human QTRTD1 clone and also wish to acknowledge Dr. Angela Walker and the Michigan Proteome Consortium for assistance with mass spectrometry analysis.
Received November 11, 2009; accepted February 9, 2010.

\section{REFERENCES}

Baranowski W, Dirheimer G, Jakowicki JA. 1994. Deficiency of queuine, a highly modified purine base, in transfer RNAs from primary and metastatic ovarian malignant tumors in women. Cancer Res 54: 4468-4471.

Boland C, Hayes P, Santa-Maria I, Nishimura S, Kelly VP. 2009. Queuosine formation in eukaryotic tRNA occurs via a mitochondrialocalized heteromeric transglycosylase. J Biol Chem 284: 1821818227.

Chong S, Curnow AW, Huston TJ, Garcia GA. 1995. tRNA-guanine transglycosylase from Escherichia coli is a zinc metalloprotein. Sitedirected mutagenesis studies to identify the zinc ligands. Biochemistry 34: 3694-3701.

Curnow AW, Kung FL, Koch KA, Garcia GA. 1993. tRNA-guanine transglycosylase from Escherichia coli: Gross tRNA structural requirements for recognition. Biochemistry 32: 5239-5246.

Deshpande KL, Katze JR. 2001. Characterization of cDNA encoding the human tRNA-guanine transglycosylase (TGT) catalytic subunit. Gene 265: 205-212.

Deshpande KL, Seubert PH, Tillman DM, Farkas WR, Katze JR. 1996. Cloning and characterization of cDNA encoding the rabbit tRNAguanine transglycosylase 60-kilodalton subunit. Arch Biochem Biophys 326: 1-7.

Emmerich B, Zubrod E, Weber H, Maubach PA, Kersten H, Kersten W. 1985. Relationship of queuine-lacking transfer RNAs to the grade of malignancy in human leukemias and lymphomas. Cancer Res 45: 4308-4314.

Garcia GA, Kittendorf JD. 2005. Transglycosylation: A mechanism for RNA modification (and editing?). Bioorg Chem 33: 229-251.

Garcia GA, Koch KA, Chong S. 1993. tRNA-guanine transglycosylase from Escherichia coli: Overexpression, purification, and quaternary structure. J Mol Biol 231: 489-497.

Garcia GA, Chervin SM, Kittendorf JD. 2009. Identification of the rate-determining step of tRNA-guanine transglycosylase from Escherichia coli. Biochemistry 48: 11243-11251.

Gunduz U, Katze JR. 1982. Salvage of the nucleic acid base queuine from queuine-containing tRNA by animal cells. Biochem Biophys Res Commun 109: 159-167.

Gunduz U, Katze JR. 1984. Queuine salvage in mammalian cells. Evidence that queuine is generated from queuosine $5^{\prime}$-phosphate. J Biol Chem 259: 1110-1113.

He B, Rong MQ, Lyakhov D, Gartenstein H, Diaz G, Castagna R, McAllister WT, Durbin RK. 1997. Rapid mutagenesis and purification of phage RNA polymerases. Protein Expr Purif 9: 142151.

Howes NK, Farkas WR. 1978. Studies with a homogeneous enzyme from rabbit erythrocytes catalyzing the insertion of guanine into tRNA. J Biol Chem 253: 9082-9087.

Huang B-S, Wu R-T, Chien K-Y. 1992. Relationship of the queuine content of transfer ribonucleic acids to histopathological grading and survival in human lung cancer. Cancer Res 52: 4696-4700.

Kasai H, Ohashi Z, Harada F, Nishimura S, Oppenheimer NJ, Crain PF, Liehr JG, vonMinden DL, McCloskey JA. 1975. Structure of the modified nucleoside Q isolated from Escherichia coli transfer ribonucleic acid. 7-(4,5-cis-dihydroxy-1-cyclopenten3-ylaminomethyl)-7-deazaguanosine. Biochemistry 14: 4198-4208.

Katze JR, Basile B, McClosky JA. 1982. Queuine, a modified base incorporated posttranscriptionally into transfer RNA: Wide distribution in nature. Science 216: 55-56.

Kirtland GM, Morris TD, Moore PH, O’Brian JJ, Edmonds CG, McCloskey JA, Katze JR. 1988. Novel salvage of queuine from queuosine and absence of queuine synthesis in Chlorella pyrenoidosa and Chlamydomonas reinhardii. J Bacteriol 170: 5633-5641.

Kittendorf JD, Barcomb LM, Nonekowski ST, Garcia GA. 2001. tRNA-guanine transglycosylase from Escherichia coli: Molecular 


\section{Chen et al.}

mechanism and role of aspartate 89. Biochemistry 40: 1412314133.

Kittendorf JD, Sgraja T, Reuter K, Klebe G, Garcia GA. 2003. An essential role for aspartate 264 in catalysis by tRNA-guanine transglycosylase from Escherichia coli. J Biol Chem 278: 4236942376.

Langgut W, Reisser T. 1995. Involvement of protein kinase C in the control of tRNA modification with queuine in HeLa cells. Nucleic Acids Res 23: 2488-2491.

Langgut W, Reisser T, Nishimura S, Kersten H. 1993. Modulation of mammalian cell proliferation by a modified tRNA base of bacterial origin. FEBS Lett 336: 137-142.

Marks T, Farkas WR. 1997. Effects of a diet deficient in tyrosine and queuine on germfree mice. Biochem Biophys Res Commun 230: 233-237.

Meier F, Suter B, Grosjean H, Keith G, Kubli E. 1985. Queuosine modification of the wobble base in tRNA ${ }^{\text {His }}$ influences 'in vivo' decoding properties. EMBO J 4: 823-827.

Morris RC, Brooks BJ, Eriotou P, Kelly DF, Sagar S, Hart KL, Elliott MS. 1995. Activation of transfer RNA-guanine ribosyltransferase by protein kinase C. Nucleic Acids Res 23: 2492-2498.

Pathak C, Vinayak M. 2005. Modulation of lactate dehydrogenase isozymes by modified base queuine. Mol Biol Rep 32: 191-196.

Pathak C, Jaiswal YK, Vinayak M. 2007. Possible involvement of queuine in regulation of cell proliferation. Biofactors 29: 159173.

Reisser T, Langgut W, Kersten H. 1994. The nutrient factor queuine protects HeLa cells from hypoxic stress and improves metabolic adaptation to oxygen availability. Eur J Biochem 221: 979-986.
Reyniers JP, Pleasants JR, Wostmann BS, Katze JR, Farkas WR. 1981. Administration of exogenous queuine is essential for the biosynthesis of the queuosine-containing transfer RNAs in the mouse. J Biol Chem 206: 11591-11594.

Romier C, Reuter K, Suck D, Ficner R. 1996. Crystal structure of tRNA-guanine transglycosylase: RNA modification by base exchange. EMBO J 15: 2850-2857.

Slany RK, Mueller SO. 1995. tRNA-guanine transglycosylase from bovine liver-Purification of the enzyme to homogeneity and biochemical characterization. Eur J Biochem 230: 221-228.

Stengl B, Meyer EA, Heine A, Brenk R, Diederich F, Klebe G. 2007. Crystal structures of tRNA-guanine transglycosylase (TGT) in complex with novel and potent inhibitors unravel pronounced induced-fit adaptations and suggest dimer formation upon substrate binding. J Mol Biol 370: 492-511.

Todorov KA, Tan XJ, Nonekowski ST, Garcia GA, Carlson HA. 2005. The role of aspartic acid 143 in E. coli tRNA-guanine transglycosylase: Insights from mutagenesis studies and computational modeling. Biophys J 89: 1965-1977.

Vandenbergh DJ, Grant MD, Severns V. 2003. A simple tandem repeat polymorphism is present in the eighth intron of FLJ12960, a possible queuine salvage enzyme gene. Mol Cell Probes 17: 319-320.

Walden TL Jr, Howes N, Farkas WR. 1982. Purification and properties of guanine, queuine-tRNA transglycosylase from wheat germ. J Biol Chem 257: 13218-13222.

Xie W, Liu XJ, Huang RH. 2003. Chemical trapping and crystal structure of a catalytic tRNA guanine transglycosylase covalent intermediate. Nat Struct Biol 10: 781-788. 

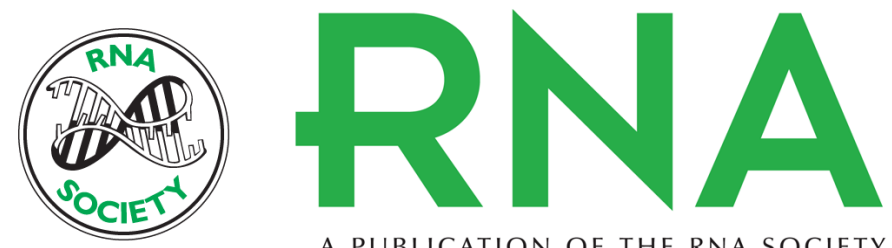

A PUBLICATION OF THE RNA SOCIETY

\section{Characterization of the human tRNA-guanine transglycosylase: Confirmation of the heterodimeric subunit structure}

Yi-Chen Chen, Vincent P. Kelly, Stefanie V. Stachura, et al.

RNA 2010 16: 958-968 originally published online March 30, 2010

Access the most recent version at doi:10.1261/rna.1997610

\section{Supplemental http://rnajournal.cshlp.org/content/suppl/2010/03/23/rna.1997610.DC1 \\ Material}

References This article cites 36 articles, 10 of which can be accessed free at: http://rnajournal.cshlp.org/content/16/5/958.full.html\#ref-list-1

\section{License}

Email Alerting Receive free email alerts when new articles cite this article - sign up in the box at the Service top right corner of the article or click here.

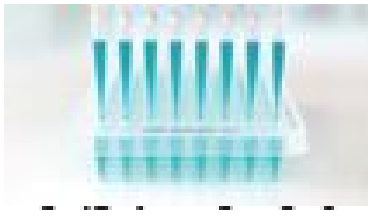

Providing Precise Solutions for your research.

To subscribe to $R N A$ go to:

http://rnajournal.cshlp.org/subscriptions 